\title{
Reducing Flooding Impacts to the Built Environment: A Literature Review
}

\author{
Mohammed Nurashikin ${ }^{1,2}$, Edwards Rodger $^{1}$ and Mohd Nordin Rumaizah ${ }^{2 *}$ \\ ${ }^{1}$ School of Mechanical, Aerospace and Civil Engineering, The University of Manchester, M13 9PL, Manchester, United Kingdom \\ ${ }^{2}$ Faculty of Architecture, Planning \& Surveying, MARA University of Technology, 40450 Shah Alam, Selangor, Malaysia
}

\begin{abstract}
The paper consists of the literature review and discussions that concerns the built environment, flooding, disaster risk management including resiliency and sustainability theory. The objective of this paper is to review any relevant works of literature in reducing the flooding impacts to the built environment in Malaysia, at the same time describing any potential improvements and current measures to handle the aftermath of flooding. Systematic literature review using reference material such as books, scholarly journals, previous studies, articles, and websites is carried out. The author also searched further for the references of the articles that were retrieved and repeated the process until a point where no new relevant articles come to light. The paper is significant in three ways; i) reducing the flood impacts by raising knowledge ii) providing responsibility measures in reducing flood from different perspectives iii) preparing ways to lessen the impacts of future flooding threats. The key findings of the paper are; a) Through knowledge application, the practice of reducing flooding impacts could be enhanced b) Flooding management should be carried out earlier before flooding attack but also remains later the event c) Disaster management plans must get ready to face with any uncertainties.
\end{abstract}

\section{Introduction}

The built environment term that involved in this paper is generally about buildings and infrastructure for example; transports, energy, water, waste and related services. Commercial properties and construction industries are also considered. Since flooding is becoming more common and frequent, planning and preparedness for the worst scenario must exist as a central consideration in development. Disaster management is an extensive area. Hence, in searching for the comprehensive literature review, the authors applied for the systematic review. Literature reviews gathered from reference materials such as websites and scholarly journals from previous studies. Different evaluations in published journals are used in this paper to come out with diversifying opinions. The authors have also provided discussions in the paper. Barakat [1], stated that disasters have a more considerable influence on the built environment of developing countries than industrialised ones. Plus, more built environment projects are expected to take place in the next 20 years that has occurred in the past [2]. Because of the increase in flooding losses, policymakers, practitioners, and members of the research community around the world are seeking a competent and efficient means of overcoming or minimising them [3]. This paper emphasises that flooding is hard to predict, and it also cannot be prevented entirely, thus reducing disaster risk impacts is a cost-effective investment in lessening future losses especially for the developing countries [4]. With all the technological advancement that the community has now, the management of flood still facing problems that need to be tackled accordingly [5]. The built environment could suffer a considerable impact when the flood happens through the damage and loss of assets, properties, and infrastructure [5-6]. The current knowledge in dealing with flood impact is still growing and developing [7]. Apart from that, there is also a need for people to take more significant roles and responsibility in enhancing the flood resiliency [8]. It is palpable that reducing flooding impacts to the built environment could be a success if the organisation or management gets together to come out with the probable strategies to cater to different needs and situations.

\section{The Built Environment and Sustainable Agenda}

There are numbers of built environment definition carried out by many other researchers. It is usually described as a physical environment, which is constructed by people to fulfil their activities [9]. Built environment involves any building and infrastructure under civil engineering together with the administration [10]. Some of the built environment professions deal with flooding circumstances including surveyors, planners, and land administrators. Those who always being referred to as practitioners always dealing with

Corresponding author: drrumaizah@salam.uitm.edu.my / rumaizah.mnordin@gmail.com 
services like consultation, design, planning, project management, and technical investigations. It is best if the built environment could work together with other extents such as planning, climate change, infrastructure, building and more major issues [11]. There is an increased sharing of understanding in the built environment study together with the literature review, but each professional and areas could bring to the table its unique offering [12]. One important thing is that the built environment is closely related to sustainability. It is a division of the overall environment, which connected to nature; thus, one will affect one another in many circumstances. The undertakings of the built environment are changing throughout the years because of the existence of an updated sustainable agenda worldwide and the latest policies and solutions [13]. A study carried out by Young [14] provides few points in guiding principles of the built environment as discussed; built environment should include the sustainability input in the economic, social and the environment through all the deals. The built resources such as building should be kept and preserved where possible to avoid any waste, involved in the conservation of history and culture [15], and responsible for larger scope such as water, infrastructure, transport, property development, and facilities [16]. Built environment should also be equipped with efficient resources to reduce building energy and emissions [16].

There is a lack of approach to face with sustainable built environment challenges [17]. The challenges are caused by larger attention being given to greening the surroundings, but a reduced attempt in making things sustainable from every aspect including management, construction, production and operation [17]. To ensure the sustainability efforts, three things need to be followed which are; sustainability assurances, ready for any drawbacks and identifying future visions [17]. In facing those challenges, the affected organisation should have the capability and capacity in technology and human resources [18]. This is because, the functionality of the built environment could be changed, including the building design, while at the same time identifying the vulnerability of which the building construction is carried out, building location, identify the challenges and come out with adaptation [18]. Towards sustainability, all components of building and environment should be done concurrently [19]. The growing of the built environment often becomes a threat with a lot of negative effects [20]. Sustainable land use and renewable energy should be used together to promote a preserved built environment while it is important to improve land use in every aspect [14]. However, considering that the world is facing with complicated climate and economics that could affect the built environment, any changes to improvement and approach will take some time [13].

\section{Raising Knowledge}

Disaster Risk Management (DRM) - DRM defined as "the systematic process of using administrative directives, organisations, and operational skills and capacities to implement strategies, policies and improved coping capacities to lessen the adverse impacts of hazards and the possibility of disaster" [21]. DRM could be a practice for the national, regional or local level [22]. DRM would also be able to lessen the disaster and encouraging the resiliency concerning society and have the capacity to deal with any activities related to disaster [23]. By using DRM as a medium in reducing flooding impacts towards the built environment, it provides guides in determining who is responsible for each strategy and offers necessary implementation towards the issues arise. Moreover, the stakeholders would be accountable for ensuring that DRM is well coordinated at all levels [22]. Since the whole process of the disaster management is integrated with one another [23], DRM should have focused on both long-term as well as short-term efforts [24].

Natural Disaster Risk Reduction (NDRR) - The knowledge and awareness about NDRR are critical to ensuring that the community could have at least some preparation towards flooding attacking the country. Having insufficient knowledge in flood would cause further problems, including lack of control during flooding recovery and leads to complicated flooding investigation and evaluation. Apposite knowledge could be earned by understanding the previous flooding experience. It is essential to choose the most relevant knowledge that fit into the real situation. It could help to contribute to the success of each decision made. The assimilation of NDRR could also involve the country policies, the connection between research activities into political elements, create linkage between researchers and stakeholders in promoting education and awareness [25]. Every part of the information should be shared accordingly to all stakeholders, staffs, communities, and others who considered vulnerable. Proper decisionmaking could be earned by having a greater receiving and delivering of information. Other things associated with knowledge utilisation are an integral part of building resiliency and creating an active flooding disaster recovery and response.

Integrated Flood Management (IFM) - IFM is a process that promotes an integrated, rather than a fragmented approach to flood management. Since improving the country disaster management requires hard work [26], IFM is promoting approaches by utilising the available resources and provide protective measures to reduce the flooding impacts. Each management and stakeholders could have unique ideas to manage flood by using the IFM. There are few critical elements of IFM [27]. The explanations of the IFM elements are based on the authors' enlightenment. i) Manage the water cycle as a whole; Any organisation involves with the flooding should be able to tackle the problems beyond the usual flood damage. The flood management team should be ready to provide any additional approaches in handling another disaster, such as health issues. Proper management of flood is the one that is efficiently done, considering wider angles in approaching things, such as knowing the types of flooding occurs, knowing the water quantity and water quality to control flooding issues accordingly. ii) Integrate land and water management; Land use 
planning and water management should combine in one synthesised plan with a standard field. The examples of the important things involved are flooding hazards mapping and useful sharing of information among authorities and management. An interdisciplinary approach is required to come out with good flood management concerns. iii) Manage risk and uncertainty; Flooding impacts could relate to fears or doubts. It also could affect the social, economic and political stability. Significant challenges are the increase in population and ever-changing economic activities. The related organisation would have to include a few advances comprises of risk identification, risk evaluation, risk reduction or risk removal by using the designated approach through policies and practices. iv) Adopt the best mix of strategies; Each of the management should carry out the applicable strategies that are adaptable, having resiliency input and adjustable to different types of flooding at any time of the year. Additionally, the management plans require the procedure for short and long-term approach. v) Ensure a participatory approach; In adapting IFM into plans, the communication between parties should be done strategically. The data and information should be delivered clearly. Decisionmaking should go through consultation and take account stakeholders' expertise. The "top-down" and "bottomup" approach, including coordination between the administrations, is a right blend in making better assessments. vi) Adopt integrated hazard management approaches; Problems handling should be done holistically. Forecasting and early warning systems are essential for managing flood. Other mechanisms that are used for flooding risks reduction are, for example, early warning system, automatic warning sirens, the Short Messaging System (SMS), telephone, fax, internet, automated telemetric rain gauges and river level recorders [28].

\section{Who is Responsible?}

Stakeholders who are dealing with flooding risks or impacts could be distinguished by several categories such as the type of participants, for example, the government, experts or the public, including the level whether it is local, regional, or national level [29. Level or type of governance also plays a role such as government-led, citizen-led or combination [30]. National authorities are at the highest power while the local stakeholder is having less power if it is based on the hierarchy. If it were related to politics, stakeholders' involvement would always have political interest, for example, the mayor or the public administration. Increasing the trust and acceptability of the local stakeholders in public administration deemed important [31]. The government-led stakeholder could manage complex issues while local-level concern for the issue is somehow limited. For instance, technical issues would need specific stakeholders for technical information sharing [32]. Local stakeholder involvement would depend on their knowledge, motivation, interest, networks or organisation they are joining [33].
Stakeholders' involvement is not merely depending on power but to their awareness including the administration and public approaches [34]. There are weaknesses in stakeholders' involvement if it is not managed efficiently, including problems and conflicts concerning political leaders and stakeholder groups [35]. Stakeholders' power, legitimacy, and urgency could help to describe whether it is proactive or reactive approaches being used in the different DRM phases [36]. This spearheads in making better distribution management of resources in between the proactive and reactive stakeholders [36]. Decision-making carried out by the stakeholders' plays an essential part in making integrated flooding management a success [37]. Moreover, stakeholders need to know what sort of information to be delivered, to whom, when and how. The aim is to offer an improved basis for the stakeholders to continuously and interactively, share and exchange DRM information in ways that help to manage disaster risks [26]. Workshops could help to gather the relevant stakeholders to become familiar with each other's accountabilities, communication, and create understanding during a crisis. Through this medium, it could promote broader viewpoints and provide opportunities for future collaboration [26]. Consequently, it is reasonable that the successfulness of the DRM could also be based on the efficiency of stakeholders in managing flooding.

In addition to that, local government is the first that should respond to flood, but this still depends on how bad the disaster is, topography, current weather and the capability of local governments in providing the effective disaster response [38]. In smaller municipalities, concern in flood mitigation is distributed among the different department levels. Attentions are given to public infrastructure and assets, any planning involved, emergency management, conservation, and public health. As for larger municipalities, flood mitigation is distributed to different plans because their related departments work separately [39]. Larger municipalities will have more power to deal with flood mitigation because of the broader working staffs and often expertise in dealing with flood events. Therefore, they could investigate structural and non-structural mitigation options. Structural flood mitigation is, for example, the structure and maintenance construction, while the non-structural flood mitigation is the measures in planning by the related departments [39]. Critical response supervision needs to be carried out when flooding strikes. Consequently, there would be high demands for the fast and enough supply of foods, medical assistance, volunteers and other necessities. The rescue leader is the one who is responsible for managing the rescue activities. It is because the leader had received training on the help and rescue during flooding disaster [40]. The leader involves in the said disaster should be able to make a timely decision while making sure all the operations are still following the plan [41]. Enough help with the transport, recovery supplies, rescue teams and debris management could help a lot in disaster management [42]. Coping capacity in the development should be involved in reducing the disaster impact [43]. 
The technical aspects, network or financial could improve the capacity development of local or community-based management [44]. Each country has different coping capacities in dealing with the flood. It depends on the countries culture, how people are dealing with risks, country laws or their social and political situation [45]. It is very tough to accept the risk level without knowing the country able to handle the disaster. Therefore, any measures taken should be based on vulnerability and capability of the country [26]. The citizens' trust towards the country will be disrupted if the flooding events keep occurring. For example, Dutch citizens think that there will be no flood and they may lose their trust in authorities of the flood is happening again. As for English citizens, they still experience flooding repeatedly [45]. Citizens do not indeed have to lose their trust in authorities, if they get help and offered enough information on flooding. Perhaps citizens could take extra care of those additional measures. Whatever the situation is, the government and authorities should take the matter seriously, and they should be responsible for anything happens [45]. On the other hand, perception and understanding will lead to the people actions in planning for and responding to flood events [46]. The understanding of resilience and capacity building should be developing further along the way with the understanding of flood risk perception [47]. Likewise, the risk perceptions could improve the resilience of the societies [48]. In managing the disaster, risk communication should be further clarified [49]. For example, a study being done towards the U.K. Environment Agency's Indicative Floodplain Maps and it is about possible flooding. It has been argued that a map provided had given misleading information. However, problems came from the public as they had lack of knowledge; thus, they cannot interpret the map in a correct way [49]. Risk communication would be able to help in understanding the impacts of flooding and help to develop more appropriate strategies. Improvement of flood risk communication raises the awareness of citizens and the business community which have had limited capability in authorities [45].

\section{Discussions}

Malaysia will be anyhow affected by large areas of flooding from experience, even though there are many precautions had been taken. The risks of flooding will always be there. Therefore, pre and post-flood planning require necessary knowledge to ensure its success. Malaysian built environment management and administrations, which previously have had no experience in handling flooding incidents, may face difficulties in dealing with such incidents effectively without a proper NDRR process in place. A strong foundation of flood knowledge process could facilitate good interaction amongst management, building users, and other key stakeholders. Reducing the impact of flooding risk could be done in several ways including a review of the design standards for the newly constructed building and the existing building. It would include reviews on water control structures, transportation structures, electrical, water control, and waste amenities. The 'culture of prevention' between NGOs and the private sector should reduce the impact of environmental hazards, in this case, flooding. 'Capacity Building' is a vital part of this agenda because of its connection to the latest scientific knowledge. Flood management plans are essential for any built environment to streamline the process of administration in handling such events. Each management of any property must develop its strategy. The strategy could be derived from other previous flooding experience and from research carried out which incorporates including theoretical aspects. The strategy must be in line with the objectives, goals, and visions of each organisation. The direction and expected outcomes may be determined in the first place. This management plan requires a robust management approach, so any issues that could prevent the built environment from achieving the objectives of any of its risk reduction plans need to be managed appropriately. A proactive work culture could also help in flooding risk reduction issues. At the same time, administrations should carry out a SWOT analysis to identify strengths, weaknesses, opportunities, and threats towards the implementation of the strategy. Understanding the topography of the built environment, getting significant information from the Malaysian Meteorological Department, identifying lowland areas and high-risk buildings constructed near steep slopes, and evaluating the current drainage system should be done even before flooding happens. As part of this plan, other risks that may arise directly or indirectly due to flooding should be identified. The causes of flooding need to be determined to ensure that the remedial work performed suits current conditions. It is also important to identify if there are any contaminants and hazardous elements in the floodwater that requires further actions. For instance, the remediation approach for a river overflowing would be different from the approach for flash floods. As for existing buildings, their current state before the flooding events occur must be evaluated. Any previous remediation done such as repairs, modifications or any other building issues should be adequately recorded. The use of strategies for flooding risk reduction should become a practice within the university sector. In ensuring the effectiveness, creating understanding among the public and getting the right approach to these risks, actions should start from the earliest planning stages. Flooding could be a challenging experience, but with an appropriate precautionary measure and knowledge on how to recover from flooding could help during and after flooding events.

\section{Facing the Future}

A paper from Josephson [50] is discussed under this section. Worst things could happen if planning towards flooding was treated as less important and when the stakeholders react only when the actual flooding occurs. The stakeholders' preparation to face with flooding should be made clear. For example, business and 
location characteristics, changes in policies, and previous flood works need to be known. The flood management planning should consider and promote sustainability, including looking at short-term and long-term strategic management decisions. Business-focused recommendations could be conceptually grouped into four broad areas; 1) planning, defined as the assessment of risk and planning specific strategies to minimise it; 2) transfer of risk, described as the purchase of insurance; 3) reinforcement of structures; and 4) protection of tangible business assets, business processes and operations. The structural measures towards the building and properties are needed for short and long-term purposes. Long-term activities could include the retrofitting of the building structures. There are different ways of lessening the flooding impact through engineering structural measures or temporary measures. The structural measures are like the construction of walls, pumps and road networks while the temporary measures are like the placement of sandbags, flood proof utilities and anything that can be done within a short time [51]. Even though things like promoting NDRR, education, and knowledge on NDRR had been delivered, the safety of the building occupants cannot be confirmed if the building was not built from the flood-proof structure [52]. Safety and regulations must be updated from time to time together with the appropriate follow up including the technical guidelines [52]. For the past two decades, the move had been changed from defending against floods known as resistance, towards adapting to them that is known as resilience [53]. Population areas affected by the flood area need to be recognised plus identifying damage to the building functions, roads, and infrastructures. This would aid flood risks assessment to other areas with comparable conditions for future use [54].

If floods occur even in small scale, it should not be ignored and should be fully well-thought-out and be measured [55]. The details about the flooding disaster should be well documented. Relevant data must be recorded appropriately to facilitate the management process if the same disaster occurs in the future [23]. There should also be a method that could keep updating the current measures to ensure their effectiveness [24]. The preparation for the flooding disasters could come from the activities that are being done such as the previous experience with disasters, property ownership, characteristics of the owner and stakeholders [50]. It is always good to raise the public awareness of flood impacts and engage with people at risk to reassure them to make their property to become more resilient [56]. The property owners and stakeholders are responsible for providing flood protection to the said properties [57]. Besides, a conceptual framework for disaster management always been critical as this could help in identifying and handling flooding challenges. This framework should be tested, and its approach is made clear. A generalisation in disaster management should be avoided unless the aspects that investigating is very vast [22]. Exchange the know-how among selected countries and therefore helps formulate best strategy and policy to mitigate the flood risk in the region [38]. Anyone who is exposed to flooding risk should have a sense of responsibility to take proactive steps towards the disaster event [47].

\section{Conclusions}

The wake of flooding could help to provide rooms to launch for a better sustainable change. Providing resilience input throughout the process is one of the ongoing betterments. The stakeholders need to have an ability to plan for the unexpected situation and tackle the situation with knowledge. Therefore, each management should have some plan, being able to manage the overall situation. The management should be expected to be able to deliver flexibility and adaptability in handling any circumstances. Appropriate decision-making is essential in accomplishing the aims of reducing natural disasters. Hence, there is a need to do an overview of understanding and practice in the multidisciplinary field to create benefits and advancement for researchers, policymakers and planners. Reducing the impact of flooding is the responsibility of everybody, including the society, government, professionals and the private sector. Every decisions and action are vital in making sure whether each of them could help in reducing the impact of flooding.

The authors would like to extend their greatest appreciation and acknowledge the Grant LESTARI 600-IRMI/DANA 5/3/LESTARI (0154/2016) to give funding and support for this research.

\section{References}

1. Barakat, S. Housing reconstruction after conflict and disaste [Online]. Available: http://www.ifrc.org/PageFiles/95751/B.d.01.Housin $\mathrm{g} \% 20$ Reconstruction $\% 20$ After\%20Conflict\%20And $\%$ 20Disaste HPN.pdf (2003)

2. Worldbank. Building a New Framework for Disaster Risk Reduction [Online]. Available: http://www.worldbank.org/en/news/feature/2015/03/ 12/building-new-framework-disaster-risk-reduction (2015)

3. Palliyaguru, R., Amaratunga, D., \& Baldry, D. Constructing a holistic approach to disaster risk reduction: the significance of focusing on vulnerability reduction. Disasters, 38(1), 45-61. (2013)

4. Chatterjee, R., Shiwaku, K., Gupta, R., Nakano, G., \& Shaw, R. Bangkok to Sendai and Beyond: Implications for Disaster Risk Reduction in Asia. International Journal of Disaster Risk Science, 6(2), 177-188. (2015)

5. UNISDR. Terminology - UNISDR [Online]. Available: https://www.unisdr.org/we/inform/terminology (2018)

6. Dube, E., Mtapuri, O. \& Matunhu, J. 'Managing flood disasters on the built environment in the rural 
communities of Zimbabwe: Lessons learnt', Jàmbá: Journal of Disaster Risk Studies 10(1), a542. (2018)

7. Cigler, B.A., 'U.S. floods: The necessity of mitigation', State and Local Government Review $\mathbf{X X}(\mathrm{X}), 1-13$. (2017)

8. Environment Agency. The evidence base for working with natural processes to reduce flood risk, [Online]. Available: http://www.apfm.info/ifm.htmhttps://www.gov.uk/g overnment/publications/working-withnaturalprocesses-to-reduce-flood-risk (2017)

9. Robin van Den Honert, Frank Thomalla, \& Pamela Box. Flood Risk in Australia: Whose Responsibility Is It, Anyway? Water, 5(4), 1580-1597. (2013)

10. Dixon, T., Connaughton, J., \& Green, S. Sustainable futures in the built environment to 2050 : a foresight approach to construction and development. Hoboken: Wiley-Blackwell (2018)

11. Designing Buildings Ltd. Built environment Designing Buildings Wiki [Online]. Available: http://www.designingbuildings.co.uk/wiki/Built_env ironment (2016)

12. Construction Industry Council - APPG for Excellence in the Built Environment [Online]. Available: $\quad$ http://cic.org.uk/services/all-partyparliamentary-group.php (2016)

13. Tony Lloyd-Jones, Ripin Kalra, Budhi Mulyawan \& Theis, M. The Built Environment Professions in Disaster Risk Reduction and Response [Online]. Available:

http://www.ifrc.org/PageFiles/95743/B.a.07.Built\% 20Environment $\% 20$ Professions $\% 20 \mathrm{in} \% 20 \mathrm{DRR} \% 20$ and $\% 20$ Response-

Guide $\% 20$ for $\% 20$ humanitarian $\% 20$ agencies DFDN \%20and\%20RICS.pdf (2009)

14. Lorenz, D., Dent, P., \& Kauko, T. Value in a changing built environment. Hoboken, NJ: Wiley Blackwell. (2018)

15. Young, R. (2012). Stewardship of the Built Environment Sustainability, Preservation, and Reuse. Washington, DC: Island Press/Center for Resource Economics.

16. USLegal. Built Environment Law \& Legal Definition [Online]. Available: http://definitions.uslegal.com/b/built-environment/ (2016)

17. Ness, D., \& Xing, K. Toward a Resource- Efficient Built Environment: A Literature Review and Conceptual Model. Journal of Industrial Ecology, 21(3), 572-592. (2017)

18. Allen, N., \& Davey, M. The Value of Constructivist Grounded Theory for Built Environment Researchers. Journal of Planning Education and Research, 38(2), 222-232. (2018)

19. Lisø, K. Integrated approach to risk management of future climate change impacts. Building Research \& Information, 34(1), 1-10. (2006)

20. Haapio, A. Towards sustainable urban communities. Environmental Impact Assessment Review, 32(1), 165-169. (2011).
21. Vogel, S. On Alienation from the Built Environment. Ethical Theory and Moral Practice, 17(1), 87-96. (2014)

22. Rivera, C., Henrik Tehler \& Christine Wamsler. Fragmentation in disaster risk management systems: A barrier for integrated planning. International Journal of Disaster Risk Reduction, 14(Part 4), 445 456. (2015)

23. Abulnour, A. H. Towards efficient disaster management in Egypt: HBRC Journal, 10, 117 126. (2014)

24. Rautela, P. Lack of scientific recordkeeping of disaster incidences: A big hurdle in disaster risk reduction in India. International Journal of Disaster Risk Reduction, 15 (Supplement C), 73 - 79. (2016)

25. Rajib Shaw, J. M. P., Joy J. Pereira. Climate Change Adaptation and Disaster Risk Reduction. (2016)

26. Lin, L. Integrating a national risk assessment into a disaster risk management system: Process and practice. International Journal of Disaster Risk Reduction. (2017)

27. APFM. IFM Concept [Online]. Available: http://www.apfm.info/ifm.htm Applied Sciences, Engineering \& Technology. (2017)

28. Koh, K.-L., Kelman, I., Kibugi, R. \& Osorio, R.-L. E. Adaptation to Climate Change. World Scientific. (2015)

29. Margerum, Richard D., A typology of collaboration efforts in environmental management. Environmental Management. 41 (4), 487-500. (2008)

30. Moore, Elizabeth A., Koontz, Tomas M. Research note a typology of collaborative watershed groups: citizen-based, agency-based, and mixed. (2003)

31. Mees, H. L. P., Driessen, P. P. J., Runhaar, H. A. C. Legitimate adaptive flood risk governance beyond the dikes: the cases of Hamburg, Helsinki and Rotterdam. Regional Environmental Change, 14 (2), 671-682. (2014)

32. Albright, E. A., and D. A. Crow. Learning processes, public and stakeholder engagement: Analyzing responses to Colorado's extreme flood events of 2013: Urban Climate, 14, 79 - 93. (2015)

33. Kuhlicke, C., Steinfuehrer, A., Begg, C., Bianchizza, C., Bruendl, M., Buchecker, M., De Marchi, B., Di Masso Tarditti, M., Hoeppner, C., Komac, B., Lemkow, L., Luther, J., McCarthy, S.S., Pellizzoni, L., Renn, O., Scolobig, A., Supramaniam, M., Tapsell, S., Wachinger, G., Walker, G., Whittle, R., Zorn, M., Faulkner, H. Perspectives on social capacity building for natural hazards: outlining an emerging field of research and practice in Europe. Environ. Sci. Policy 14 (7) 804 814. (2011)

34. Thaler, T.A., Priest, S.J. Partnership funding in flood risk management: new localism debate and policy in England. (2014)

35. Thaler, T., and M. Levin-Keitel. Multi-level stakeholder engagement in flood risk management A question of roles and power: Lessons from England: Environmental Science \& Policy, 55, 292 301. (2016) 
36. Mojtahedi, M. \& Oo, B. L. Critical attributes for proactive engagement of stakeholders in disaster risk management. International Journal of Disaster Risk Reduction, 21, 35-43. (2017)

37. Begg, Callsen, Kuhlicke \& Kelman. The role of local stakeholder participation in flood defence decisions in the United Kingdom and Germany. Journal of Flood Risk Management. (2017)

38. Osti \& Nakasu. Lessons learned from southern and eastern Asian urban floods: from a local perspective. Journal of Flood Risk Management, 9(1), 22-35. (2016)

39. Consoer \& Milman. Opportunities, constraints, and choices for flood mitigation in rural areas: perspectives of municipalities in Massachusetts. Journal of Flood Risk Management. (2017)

40. Chou Shuo- Yan \& Dayjian Chen. "Emergent disaster rescue methods and prevention management", Disaster Prevention and Management: An International Journal, 22 Issue: 3, 265-277. (2013)

41. Fleischmann, M., Beullens, P., Bloemhof-Ruwaard, J.M. and Wassenhove, L.N. "The impact of product recovery on logistics network design", Product and Operation Management, 10, No. 2,156-173. (2000)

42. Kara, B.Y., Erkut, E. and Verter, V. "Accurate calculation of hazardous materials transport risks", Operation Research Letters, 31 No. 4, pp. 285-292. (2003)

43. Hagelsteen, M., and J. Burke. Practical aspects of capacity development in the context of disaster risk reduction: International Journal of Disaster Risk Reduction, 16, 43 - 52. (2016)

44. Steelman, Toddi A., Carmin, Jo Ann. Community based watershed remediation: connecting organizational resources to social and substantive outcomes. In: Rahm, Diane (Ed.), Toxic Waste and Environmental Policy in the 21st Century United States. McFarland, Jefferson, NC, 145-178. (2002)

45. Brinke, W. B. M. T., Knoop, J., Muilwijk, H. \& Ligtvoet, W. Social disruption by flooding, a European perspective. International Journal of Disaster Risk Reduction, 21(Supplement C), 312 322. (2017)

46. Raaijmakers, R., Krywkow, J. \& van der Veen, A. Flood risk perceptions and spatial multi-criteria analysis: an exploratory research for hazard mitigation. Natural Hazards, 46(3), 307-322. (2008)

47. Birkholz, S., M. Muro, P. Jeffrey \& Smith, H. M. Rethinking the relationship between flood risk perception and flood management. Science of The Total Environment, 478 (Supplement C), 12 - 20. (2014)

48. Burns, W. J. \& Slovic, P. Risk Perception and Behaviors: Anticipating and Responding to Crises. Risk Analysis, 32(4), 579-582. (2012)

49. Brown, J. D. \& Damery, S. L. Managing Flood Risk in the UK: Towards an Integration of Social and Technical Perspectives. Transactions of the Institute of British Geographers, 27(4), 412-426. (2002)
50. Josephson, A., H. Schrank, and M. Marshall. Assessing preparedness of small businesses for hurricane disasters: Analysis of pre-disaster owner, business and location characteristics: International Journal of Disaster Risk Reduction, 23, 25-35. (2017)

51. Zevenbergen C., K. Kolaka, S. van Herk, M. Escarameia, B. Gersonius, D. Serre, N. Walliman. Assessing quick wins to protect critical urban infrastructure from floods: a case study in Bangkok, Thailand: Journal of Flood Risk Management. (2015)

52. Sakurai, A. \& Sato, T. Promoting Education for Disaster Resilience and the Sendai Framework for Disaster Risk Reduction. Journal of Disaster Research, 11(3), 402-412. (2017)

53. Jong, Pieter, and B. M. v. den. Between tradition and innovation: developing Flood Risk Management Plans in the Netherlands: Journal of Flood Risk Management, 10, 155-163. (2017)

54. Vu, T. T. \& Ranzi, R. Flood risk assessment and coping capacity of floods in central Vietnam. Journal of Hydro-environment Research, 14 (Supplement C), 44 - 60. (2017)

55. Cadag, J. R. D., Petal, M., Luna, E., Gaillard, J. C., Pambid, L. \& Santos, G. V. Hidden disasters: Recurrent flooding impacts on educational continuity in the Philippines. International Journal of Disaster Risk Reduction, 25 (Supplement C), 72 81. (2017)

56. Defra. Understanding the risks, empowering communities, building resilience: the national flood and coastal erosion risk management strategy for England. London: The Stationery Office. (2011)

57. Wedawatta, G., Ingirige, B., \& Proverbs, D. Small businesses and flood impacts: the case of the 2009 flood event in Cockermouth. Journal of Flood Risk Management, 7(1), 42-53. (2014) 